\title{
Unusual cardiogenic shock due to pheochromocytoma: Recovery after bridge-to-bridge (extracorporeal life support and DeBakey ventricular assist device) and right surrenalectomy
}

\author{
J.-M. Grinda, MD, ${ }^{a}$ M.-O. Bricourt, MD, ${ }^{a}$ S. Salvi, MD, ${ }^{a}$ M. Carlier, MD, ${ }^{b}$ F. Grossenbacher, MD, ${ }^{b}$ C. Brasselet, MD, ${ }^{\mathrm{c}}$ and \\ J.-N. Fabiani, MD, ${ }^{\text {a }}$ Paris and Reims, France
}

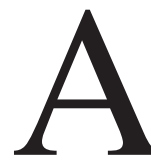

cute adrenergic cardiomyopathy resulting in intractable pulmonary edema and life-threatening cardiogenic shock is an unusual revelation of a pheochromocytoma. ${ }^{1-4}$ Dealing with such a patient, we have performed a bridge-to-bridge (extracorporeal life support [ECLS] secondarily switched for a DeBakey axial pump ventricular assist device) associated to a right surrenalectomy, allowing cardiac function recovery.

\section{Clinical Summary}

A 49-year-old man with no previously known pathology or risk factors complained of brutal abdominal pain, vomiting, headache, and malaise. On arrival to his referring hospital, he presented with a massive pulmonary edema, followed by cardiogenic shock and cardiac arrest requiring cardiopulmonary resuscitation. Initial laboratory findings showed troponin I and pro-brain natriuretic peptid levels at $0.23 \mu \mathrm{g} / \mathrm{L}$ and $5667 \mathrm{pg} / \mathrm{mL}$, respectively (normal, $<0.06 \mu \mathrm{g} / \mathrm{L}$ and $<84 \mathrm{pg} / \mathrm{mL}$, respectively). Arterial blood gases revealed a partial oxygen pressure of $218 \mathrm{~mm} \mathrm{Hg}$ at a fraction of inspired oxygen of 1 . Electrocardiography did not identify signs of ischemia or infarction, and chest radiography showed bilateral infiltration consistent with pulmonary edema. An echocardiogram revealed a severe global hypokinesia (left ventricular ejection fraction, 12\%) without ventricular dilatation, no valvulopathy, no pulmonary artery hypertension, and a nonincreased septal thickness. Hemodynamic and respiratory status worsened despite mechanical ventilation, volume expansion, and an intake of dobutamine $(8 \mu \mathrm{g})$ and norepinephrine $(2 \mu \mathrm{g})$. The results of coronorography were normal, and during the procedure, an intraaortic balloon pump was introduced. A thoracoabdominal computed tomographic (CT) scan revealed a $3 \times 3$-cm mass in the right adrenal gland. The diagnosis was orientated toward pheochromocytoma, and initial dosages of catecholamines were provided.

We were approached as the patient's condition got worse with signs of multiorgan failure. We then decided to implant an ECLS

From the Department of Cardiovascular Surgery, European Hospital Georges Pompidou, ${ }^{\text {a }}$ Paris, France, and the Department of Anaesthesiology and Intensive Care ${ }^{\mathrm{b}}$ and the Department of Cardiology, "Maison Blanche" Hospital, Reims, France.

Received for publication Oct 27, 2005; revisions received Nov 25, 2005; accepted for publication Dec 1, 2005.

Address for reprints: Jean Michel Grinda, MD, Department of Cardiovascular Surgery, Hôpital Européen Georges Pompidou, 20 rue Leblanc 75015, Paris, France (E-mail: jean-michel.grinda@hop.egp.ap-hop-paris.fr).

J Thorac Cardiovasc Surg 2006;131:913-4

$0022-5223 / \$ 32.00$

Copyright () 2006 by The American Association for Thoracic Surgery

doi:10.1016/j.jtcvs.2005.12.021 device (Medos Delta stream) by means of peripheral cannulation (common femoral artery and vein) in the referring hospital's emergency department (located $200 \mathrm{~km}$ from our department).

Medical transport, although risky, then ensued safely by road to our institution. ECLS provided an adequate flow (4 L/min), allowing norepinephrine and dobutamine disruption on day 2. The dosage of catecholamines was consistent with the presumed diagnosis of pheochromocytoma: both epinephrine and norepinephrine levels were high, at $12.5 \mathrm{nmol} / \mathrm{L}$ and $3.5 \mathrm{nmol} / \mathrm{L}$ (normal, $<4$ $\mathrm{nmol} / \mathrm{L}$ ), respectively, and the urinary vanyl mandelic acid value was $81.23 \mathrm{mg} / 24$ hours (normal, $<7 \mathrm{mg} / 24$ hours).

At day 4 on ECLS, the patient presented with an intractable hypertension, despite triple therapy (calcium-channel blocker, $\alpha$ - $\beta$-blocker, and vasodilator), which was soon followed by a massive pulmonary edema. We decided to carry on with the surgical treatment of pheochromocytoma and the placement of a left ventricular assist device (DeBakey axial pump) as a bridge to recovery. ${ }^{5}$

ECLS was used as extracorporeal circulation to achieve the surgical procedure, including sternotomy, right subcostal laparotomy, right surrenalectomy, and DeBakey axial pump ventricular assist device (Micromed) implantation. Histologic examination of the adrenal gland confirmed the diagnosis of pheochromocytoma, and cardiac biopsy specimens showed slight nonspecific changes (hypertrophy and fibrosis). Blood and urinary samples for the dosage of catecholamines were obtained on postoperative days 10 and 30. Norepinephrine was at 10.9 and $4.8 \mathrm{nmol} / \mathrm{L}$, and epinephrine was at $0.54 \mathrm{nmol} / \mathrm{L}$ and nondetectable, respectively. Urinary metanephrine was $3.8 \mu \mathrm{mol} / 24$ hours (normal, $<3.7 \mu \mathrm{mol} / 24$ hours) and $1.3 \mu \mathrm{mol} / 24$ hours, respectively. Progressive cardiac function recovery was confirmed by means of echocardiography and an isotopic scintigraphy, allowing DeBakey ventricular assist device explantation on day 70. The postoperative course was uneventful, and the patient was discharged from the hospital on day 90. At 12 months' follow-up, he has recovered a normal cardiac function (left ventricular ejection fraction, 60\%). The thoracoabdominal control CT scan shows no abnormality.

\section{Discussion}

Unusual presentations of pheochromocytoma have been reported, including dilated cardiomyopathy, pulmonary edema, cardiogenic shock, sudden death, and even 2 cases of late diagnosis realized after cardiac transplantation for dilated cardiomyopathy. ${ }^{4}$ The diagnosis is difficult and frequently made postmortem. To our knowledge, this case is the first requiring mechanical circulatory support ever published. For this patient, the diagnosis was rapidly but fortuitously established on the basis of a systematic CT scan 
and later confirmed by dosages of catecholamines. The institution of an early aggressive treatment was life saving.

Compared with the scheduled device implantation in patients deteriorating on the waiting list, management of emergencies requiring circulatory support is still a challenging situation. We have developed in our unit a mobile kit of emergency circulatory support to deal with this problem. This ECLS has become a useful adjunct to our cardiac assist device program, allowing patient transfer and secondary implantation of a more long-term sophisticated device.

As expected in this catecholamine-induced cardiomyopathy, the patient recovered after surgical resection of the tumor, but recovery is not so fast as to allow the use of an ECLS device alone, and implantation of a long-term device was mandatory.

\section{Conclusion}

Diagnosis and treatment of cardiogenic shock caused by pheochromocytoma is difficult and can end in fatal evolution. This case emphasizes the need for an early aggressive treatment to improve the outcome of this surgically curable pathology.

\section{References}

1. Kizer JR, Koniaris LS, Edelman JD, St John Sutton MG. Pheochromocytoma crisis, cardiomyopathy, and hemodynamic collapse. Chest. 2000;118:1221-3.

2. Mohamed HA, Aldakar MO, Habib N. Cardiogenic shock due to acute hemorrhagic necrosis of a pheochromocytoma: a case report and review of the literature. Can J Cardiol. 2003;19:573-6.

3. Liao WB, Liu CF, Chiang CW, Kung CT, Lee CW. Cardiovascular manifestations of pheochromocytoma. Am J Emerg Med. 2000;18: 622-5.

4. Dalby M, Burke M, Radley-Smith R, Banner N. Pheochromocytoma presenting after cardiac transplantation for dilated cardiomyopathy. J Heart Lung Transplant. 2001;20:773-5.

5. Grinda JM, Latremouille Ch, Chevalier P, D'Attelis N, Boughenou F, Guillemain R, et al. Bridge to transplantation with the DeBakey VAD axial pump: a single center report. Eur J Cardiothorac Surg. 2002;22: 965-70.

\section{Percutaneous occlusion of a pseudoaneurysm evolving after homograft aortic valve and root replacement with the Amplatzer muscular ventricular septal defect occluder}

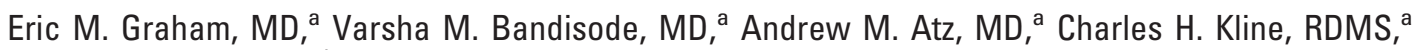

Marian H. Taylor, MD, ${ }^{b}$ and John S. Ikonomidis, MD, PhD, ${ }^{c}$ Charleston, SC

A ortic root replacement with aortic homograft has yielded good results in appropriate patients. Aortic pseudoaneurysms are a rare postoperative complication, potentially leading to reoperation with significantly higher surgical mortality. ${ }^{1}$ We describe a case in which a left ventricular outflow tract pseudoaneurysm is successfully occluded with transcatheter device closure in a patient at high risk for reoperation.

\section{Clinical Summary}

A 40-year-old woman presented with a history of a bicuspid aortic valve with severe insufficiency, ascending aortic aneurysm, and hemiarch aneurysm. After discussion of the various treatment options, she

\footnotetext{
From the Divisions of Pediatric Cardiology, ${ }^{\mathrm{a}}$ Cardiology, ${ }^{\mathrm{b}}$ and Cardiothoracic Surgery, ${ }^{\mathrm{c}}$ Medical University of South Carolina, Charleston, SC.

Received for publication Nov 8, 2005; accepted for publication Nov 15, 2005.

Address for reprints: Varsha M. Bandisode, MD, Medical University of South Carolina, 165 Ashley Ave, PO Box 250915, Charleston, SC 29425 (E-mail: bandisvm@musc.edu).

J Thorac Cardiovasc Surg 2006;131:914-6

$0022-5223 / \$ 32.00$

Copyright $\odot 2006$ by The American Association for Thoracic Surgery doi:10.1016/j.jtcvs.2005.11.016
}

underwent surgical replacement with a 22-mm homograft aortic valve, root, and ascending aorta. Her midterm postoperative course was complicated by gram-negative endocarditis and dehiscence of the homograft. Her aortic homograft was rereplaced 22 days after initial intervention and was complicated by uncontrollable bleeding from a posterior annular suture line. An anterior pericardial baffle was created and decompressed to the right atrial appendage, resulting in hemostasis. At 48 days after the second surgical intervention, follow-up revealed a persistent and increasing left-to-right shunt. At surgical re-exploration, an unsuccessful attempt (caused by continued bleeding) was made to repair the homograft at the posterior annulus, requiring replacement of the pericardial baffle.

Serial computed tomographic angiography revealed closure of the left-to-right shunt, but a contained pseudoaneurysm remained in the lateral aspect of the left ventricular outflow tract directed posteriorly between the left atrium and the aortic arch and draped by the left main coronary artery. Serial evaluations revealed progressive enlargement of the pseudoaneurysm with tenting of the left main coronary artery at its bifurcation.

Given her multiple reoperations, she was referred for transcatheter device occlusion of the pseudoaneurysm. Institutional review board approval for compassionate use of the device, as well as informed consent, was obtained. Transthoracic echocardiography revealed a $3.5 \times 1.6-\mathrm{cm}$ pseudoaneurysm located posteriorly and leftward of the aortic valve. The neck to the pseudoaneurysm originated under the aortic valve within the left ventricular outflow 